\title{
The Perspectives of Outsourcing of Internal Audit Functions in Albania
}

\author{
Marsel Sulanjaku \\ Phd. Lecturer in Finance \& Accounting Department. Faculty of Economics, University of Elbasan. "L5 Maji" \\ Pall. Nr 730, H4/C Elbasan (3001) Albania. Email: marsel.sulanjaku@uniel.edu.al
}

\author{
Ardita Todri \\ Phd. Lecturer in Finance \& Accounting Department. Faculty of Economics, University of Elbasan. "L.D.H. Myzyri" \\ Pall. Nr 10, H3/C, Elbasan (3001) Albania. Email: ardita.todri@uniel.edu.al
}

\section{Doi:10.5901/ajis.2015.v4n3s1p395}

\section{Abstract}

Outsourcing of the products and services to other companies is already a very used option that in general aims to have more qualified products or services with lower costs. As in the other sectors the professional auditors offer to outsource a company's internal control services in order to increase their quality or to lower the internal auditing system costs. By outsourcing, a company can depute the auditing tasks that can be performed in a small amount of time and an internal audit structure can be too expensive to maintain. Through this study we evaluate an analytical overview of the internal auditing outsourcing by summarizing the factors that drive the company's managers or stakeholders to partially or totally outsource the internal control auditing. The benefits from the usage of the internal auditing outsource can vary in different situation depending on the specifics of the economic unit. The aim of this study is to analyze the benefits of audit outsourcing and to evaluate the auditing outsourcing perspective in Albanian market. The methodology used in the preparation of this paper will be that of the utilizing the foreign and national literature, and the utilization of the interviews with the companies and auditors that have experience in auditing outsourcing in Albania.

Keywords: outsourcing, internal audit, evaluation, benefits

\section{Introduction}

Auditing is a systematic process of objectively obtaining and evaluating the information or financial statements to certify the fair representation of the information, and communication of the results to interested users. The need for internal audit is becoming more evident as organizations and the economic transactions are become more intense and complex. The complexity of the modern economic transactions and the increase in the companies with branches and subsidiaries has made the supervising of such companies a very hard task. Internal audit assist the decision makers to better manage their company resources by providing information regarding the risks that are being managed within the organization and taking actions to minimize those risks. The risks of the organizations differ in nature and number and managing those risks effectively is the main objective of internal audit. There are different definition for the internal auditing. The institute of internal auditors defines Internal auditing as an independent, objective assurance and consulting activity designed to add value and improve an organization's operations. It helps an organization accomplish its objectives by bringing a systematic, disciplined approach to evaluate and improve the effectiveness of risk management, control, and governance processes. $^{1}$

\section{General Objectives and Categories of Internal Auditing}

Over years the internal audit functions have changed rapidly. From traditional controller, the internal auditing is expected to minimize overall risk that the company can have by adding value to the business. The internal control can be classified into three categories: management control systems, administrative control systems and accounting control systems.

- Management controls generally are more comprehensive and compose the main objective of the organization 
where are included all the plans and politics, procedures and the practices that are needed for the management to fulfill the organizations objectives.

- Administrative controls are the procedures or the recordings that are connected with the decision making processes and enable the management to make authorized actions.

- Accounting controls cover the procedures and documentation that is related with the protections of the assets and the reliability of the financial statements

The responsibilities of the internal auditor are increasing with the sophistication of the economy and the business organizations. From these responsibilities we can list: examination of the accounts to determine their accuracy and reliability, review the company policies, operations and procedures to agree with expectations and standards, establish and programming adequate accounting system and effective forms of control, providing advice to the management in respect to the changes in the economy and their changes in economy, supervise the progress of the company etc. Although the responsibilities of the internal audits are various in number and increasing due to political and economical changes and the complexity of the transactions and business organizations the internal auditors' objectives can be grouped into four main categories: ${ }^{2}$

- Enforcement of law: from this perspective the internal auditors control if the organizations operations are conform regulations, rules and procedures;

- Economical: from this perspective the internal audit ensures the managements if the company is efficient and has a designated use of assets;

- Safeguarding assets: Safeguarding the investments against losses, abuse, mismanagement, fraud or corruption is another main objective of internal auditing that is accomplished by establishing a system of authorizations and through a good and effective accounting system;

- Integrity and reliability of information: Another objective of internal auditing is controlling the financial accounts and data, and fair disclosure of these data in periodic reports.

The word "audit" is very often related to the external audit, which is carried out by accountants. In today's reality the internal audit is not necessarily to have accountancy education or backgrounds, they can have administrative background or different skills and technical qualifications, depending on the sector in which their company operates. As the internal auditors education or background can be different they all should have in common other characteristics like strong ethical values, effective communication, strong analytically reasoning, good writing and reporting skills and being good negotiators. The ethical values of an auditor are obligatory and are regulated by the code of ethics, which is based on principles of integrity, objectivity, confidentially and competency. ${ }^{3}$ The quality of the internal auditors is regulated by the Institute of Internal Auditors Standards and they have been adopted by organizations all over the world. The internal auditing standards explain the best practice principles related to the internal auditing. The standards also establish the basis for the evaluation of internal audit performance. ${ }^{4}$ Depending on the objectives the internal audit can be classified into three categories:

Regular or compliance audit: Its objective which is to establish if they met certain criteria defined by a competent authority. These criteria are usually specific entities or sectors of

activities such as: compliance with management decisions or policies; compliance procedure manuals relating to the conduct of operations; compliance with contract terms; legal compliance and other external restrictions; ensuring an atmosphere of moral- ethical thing etc.

Audit of effectiveness or performance: In this type of audit criteria are not fixed, they change each time depending on the reasoning of auditors that look at what are the best, effective, reliable and timely solutions based on emerging internal and external cyclical. Effective audit can be viewed from two angles: management audit and operational audit.

Financial audit: relies in collecting audit evidence about the entity's financial statements and use these samples to assess their compliance with preset criteria. The financial auditing represents the activity of professional examination of the information in the purpose of expressing a responsible and independent opinion, in relation to a standard, quality criteria aiming at improving the use of information

According to a survey conducted by Ernst \& Young among the priorities and expectations of stakeholders and management from internal auditing have clearly shifted from financial controls to risk coverage and business relevance

\footnotetext{
2 Colbert, J. L. (1998). Internal auditors and assurance services. Internal Auditing 13(6),

${ }^{3}$ www.iia.org.uk

${ }^{4}$ https://www.iia.org.uk/resources/delivering-internal-audit/
} 
operations. According to the survey the management and the stakeholders the priorities from the internal auditing would rather be 5 : Improving the risk assessment process; Enhancing the ability to monitor emerging risks; becoming more relevant to achieving the organization's business objectives; reducing overall internal audit function costs without compromising risk coverage; identifying opportunities for cost savings in our business

The internal audit helps the management to better control their organization and assisting them in their decision making routines by adding value to their organizations. Internal auditing is a very useful system in assisting the stakeholders to increase the value of the organization, but not every organization can implement an internal control. Internal control may be expensive and can be unaffordable by small companies.

\section{Outsourcing of Internal Audit}

Contemporary organizations are increasingly information-dependent and knowledge intensive, and engage in extremely specialized and sophisticated operations across industries and sectors globally. In this radically changed business environment, the internal audit function has become a major support function for management, the audit committee, the board of directors, the external auditors, as well as key stakeholders. ${ }^{6}$ In recent years, outsourcing has become a common practice for companies operating in different sectors and have to take decision that involves different sectors expertise or skills. As economists are often quick to point out. In the move toward increased efficiency, it is part of the natural economic process to try to find better, more efficient and less costly ways to do things. Outsourcing is the process in which the management purchases the services of internal auditing from outside. By outsourcing, a company can depute the auditing tasks that can be performed in a small amount of time and an internal audit structure can be too expensive to maintain. There is a wide range of literature that discusses numerous factors that influence outsourcing decisions, including products or professional services that can affect the quality and the cost of this products. ${ }^{7}$ As the well known author (Salvetti J. , 1995) cites "Do what you do best, outsource the rest", it is obvious that in a complex economic transactions where more interest areas intercept with each-other it is very difficult to maintain a high quality with optimal cost of performing tasks in all these sectors. ${ }^{8}$ In auditing sector already is very popular that the companies have the trend to outsource their internal control systems to professional auditing companies. Entrusting the internal controls of a to an external service provider offers several benefits. By outsourcing certain functions, or in some cases the whole internal control, organizations can benefit from a much broader range of skill sets and access to specialty services that bring best practice knowledge to the client company and achieve economies of scale and economic efficiencies. Outsourcing also allows management to stay focused on core business operations, rather than worry about managing and maintaining certain non-core business processes. ${ }^{9}$ The Institute of Internal Auditors (IIA), recognizes that many "partnering" arrangements with outside providers have been effective in helping organizations obtain internal audit services that contribute to management's strategic objectives, but in cases where total outsourcing is selected as the method for obtaining internal audit services, The IIA believes that oversight and responsibility for the internal audit activity cannot be outsourced. ${ }^{10}$ There are a number of factors to be considering when outsourcing an internal control such as the available resources, size of the organizations, quality of the actual internal control, cost of the internal control. Analyzing of the available resources is the first step in considering the internal control outsourcing. If the available resources are scarce or not available in certain situation the outsourcing of the internal control may be one option. The size of the organization is proportionally related to the internal control outsourcing. The bigger the size of the company the greater the needs to outsource the internal control. This is obvious, because the size of the company raises the complexity of the transactions and the expertise level needed for a properly internal control service. ${ }^{11}$ On other side small organizations may find necessary to explore outsourcing due to the inability to hire permanent or fulltime internal auditors, and thus reducing the fulltime internal auditors costs. There are several advantages that one company can obtain through fully or

\footnotetext{
${ }^{5}$ http://www.mcser.org/ichss2015/index.php/payment

${ }^{6}$ Chapman, C., and U. Anderson, Implementing the Professional Practices Framework (Altamonte Springs, FL: The Institute of Internal Auditors, 2002

7 Spiegel J., 1993, "Horizontal Subcontracting," RAND Journal of Economics 24n4:570-590

${ }^{8}$ Salvetti J.R. and Schell N.D., 1995, Is Outsourcing Right for You?, Bank Marketing, October 1995

${ }^{9}$ Verschoor, C. C. (1992). Evaluating outsourcing of internal auditing. Management Accounting, 73(8),

10 Sridhar ramamoorti, (2003), internal auditing:history, evolution, and prospects, The Institute of Internal Auditors Research Foundation

11 Subramaniam, N., Ng, C. and Carey, P. (2004). Outsourcing internal audit services: An empirical study on Queensland government entities. Australian Accounting Review, 14(3),
} 
partially outsourcing of internal audit such as: ${ }^{12}$ Providing the organization with a greater level of assurance and risk coverage, reducing the administrative costs, boost operational efficiency and performance, better controlling and risk management, identify and manage emerging risks more effectively, provide broader skills sets and deeper industry specialization, supply intellectual capital, offering proactive insights and recommendations on leading practices, provide access to leading-edge tools and methodologies such as data analytics, execute on business strategy more effectively and achieve strategic goals and objectives, transfer knowledge and capabilities to the organization. Outsourcing enhances the auditor in understanding the business environment policies and procedures thereby increasing the credibility of the financial reports and reducing their liability. By transferring the special services to specialized auditors, the company can focus in its core operations and having more possibilities in facilitating the achievement of company policies such as budget targets achieving and its goals. Using internal quality outsourcing may have disadvantages like: the outsourcing of internal control is not convenient as a service and it can also have high cost depending on a company's characteristics. Another disadvantage in using outsourcing is when the company uses the same firm for internal and external audit services leading to inferior quality reports. The external consultant don't know as an internal auditor the environment and the culture of the company as well as an internal auditor hired knows, and this can make harder the access to a series of relevant information, because the internal audit hired know where and what to search $\cdot{ }^{13}$ Another disadvantage of the outsourcing is the availability of the outsourced internal auditor is not all the time, and every moment Outsourcing has been criticized as a practice that destroys jobs and praised as a way to cut costs and remain competitive. The accounting profession has utilized outsourcing to avail itself of expertise that is not available within the firm and to cut the cost of offering a variety of accounting and tax services. ${ }^{14}$

To determine if outsourcing is the appropriate alternative to conduct the internal control, there are several factors that should be taken in consideration and analyzed like ${ }^{15}$ : the capabilities, expertise and the skills of the actual internal control employees to analyze the risks appropriately, the actual cost of the internal control system, the ability of the internal audit to lead the company strategies upon changes in the market, and if the actual internal quality staff is creating added value to the company.

\section{The Perspectives of Outsourcing in Albania}

As mentioned above the main benefits of outsourcing are obtaining higher quality services and lowering the administrative costs of an internal control system. The outsourcing, generally is adopted by big companies who want to focus on their business hardcore and achieving high professional services in every department, and by relatively small companies who do not have many transaction as to pay a full time employee for the internal control.

Albania economy is a fragile economy, where $\sim 90 \%$ of the business are small business that have between 1 to 9 employee, $\sim 9 \%$ are medium sized companies where the employee number is between $10-200$ employee and only almost $\sim 0.4 \%$ are big companies with over 200 employee ${ }^{16}$. The small companies generally outsource the entire book keeping system to the certified accountants, as they do not have many transactions and it is costly to hire a full time professional. The financial statement of these companies are generally prepared for fiscal and tax purposes. The medium sized companies, partially outsource some of the internal control procedures to the certified accountants, and mostly to the certified public accountant (CPA). The most outsourced functions of internal controls include book keeping and preparation of the financial statements for tax and fiscal purposes. Regarding the large companies, in Albania they generally do not outsource the internal auditing, in exception of multination's companies, where the internal auditing is partially performed from the parent company.

\section{Conclusions}

The dynamic changes in technology and marketing induced by the high competition of the global market has made companies to become more focused in their core activities. Only by focusing on what they can do best, a company can

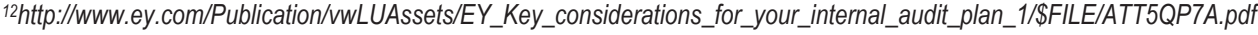

${ }^{13}$ Ernest\&Young, (2005), The merits of outsourcing your internal audit function, December, available on-line at www.ey.com

${ }_{14}$ Mintz, Steven (2004). The Ethical Dilemmas of Outsourcing. The CPA Journal 74(3): 6, 8-10 (March)

${ }^{15}$ Carey, P., N. Subramaniam, and K. C. W. Ching. 2006. Internal audit outsourcing in Australia. Accounting and Finance 46.

${ }^{16} \mathrm{http}: / / w w w . e k o n o m i a . g o v . a l /$
} 
resist the high competition of global economy. Internal control is a very important task, especially in large companies that needs effectiveness and experience to be performed according to the standards. Maintaining an effective and efficient internal control department can be a challenging and a costly task. In this perspective there is tendency of large companies to outsource this task to professional auditing companies with the scope to increase its effectiveness and in the same time to reduce the costs. Shifting from tradition cost management accounting to strategic cost management accounting. The aim of this research is to study the actual situation and the tendency of the Albanian business in outsourcing the internal control functions. We have reached in some consistent generalizations based in different interviews with certified public accountants and selected businesses to better understand the extensions of internal control outsourcing and its perspective in Albanian market.

The large companies in Albania are already benefiting from the advantages of internal control outsourcing where the most used element of internal control are the liabilities, the collections of the debt from the clients. The big companies are hiring specialized companies in performing these tasks. A full outsourcing of internal control functions are rarely observed in Albanian market. According to the interviews conducted there are potentials for more outsourcing of internal controls functions in Albania, especially for the medium sized companies, and the main factor is lowering the internal control costs. By outsourcing the internal controls these categories of companies do not have the necessity to employ a full time employee for not intense internal control procedures. Although there is a potential market for outsourcing of the internal control function of the medium sized companies in Albania there is a lack of professional companies in the market to offer these services in a standardized and effective manner. In this perspective we encourage the accounting and auditing professionals, CA and CPA to focus more on the outsourcing of the auditing services in the Albanian market, because the demand for such services is expected to increase. The training of the professionals to deliver these services in standardized and an efficient way is a challenging task. Although a challenging task the outsourcing of the internal controls of medium sized companies is a potential market for the professional accountant and can be applied without impairing the audit independence in regards to non-audit services.

\section{References}

Carey, P., N. Subramaniam, and K. C. W. Ching. 2006. Internal audit outsourcing in Australia. Accounting and Finance 46:

Chapman, C., and U. Anderson, Implementing the Professional Practices Framework (Altamonte Springs, FL: The Institute of Internal Auditors, 2002

Colbert, J. L. (1998). Internal auditors and assurance services. Internal Auditing 13(6),

Ernest\&Young, (2005), The merits of outsourcing your internal audit function, December, available on-line at www.ey.com

Mintz, Steven (2004). The Ethical Dilemmas of Outsourcing. The CPA Journal 74(3): 6, 8-10 (March)

Salvetti J.R. and Schell N.D., 1995, Is Outsourcing Right for You?, Bank Marketing, October 1995

Spiegel J., 1993, "Horizontal Subcontracting," RAND Journal of Economics 24n4:570-590

Sridhar ramamoorti, (2003), internal auditing:history, evolution, and prospects, The Institute of Internal Auditors Research Foundation

Subramaniam, N., Ng, C. and Carey, P. (2004). Outsourcing internal audit services: An empirical study on Queensland government entities. Australian Accounting Review, 14(3),

Verschoor, C. C. (1992). Evaluating outsourcing of internal auditing. Management Accounting, 73(8),

www.iia.org.uk

http://www.ekonomia.gov.al/

http://www.ey.com/Publication/vwLUAssets/EY_Key_considerations_for_your_internal_audit_plan_1/\$FILE/ATT5QP7A.pdf

http://www.mcser.org/ichss2015/index.php/payment

http://www.theila.org/guidance/standards-and-guidance/ippf/definition-of-internal-auditing/?search\%C2\%BCdefinition

https://www.iia.org.uk/resources/delivering-internal-audit/ 